\title{
A Specific Multi-Approach Intervention for Adhesive Capsulitis: A Case Report
}

\author{
Ruivo RM ${ }^{1, *}$, Donatelli $\mathbf{R}^{2}$, Parraca JA ${ }^{3}$ \\ ${ }^{1}$ Faculdade de Motricidade Humana, Universidade de Lisboa, CIPER, Lisbon, Portugal \\ ${ }^{2}$ Las Vegas Physical Therapy \& Sport, Adjunct professor at University of Las Vegas \\ ${ }^{3}$ Department of Sport and Health, Research Center in Sports, Health Sciences and Human Development, Science and \\ Technology School, University of Évora, Évora, Portugal
}

Received: August 09, 2017; Accepted: August 17, 2017, 2014; Published: September 18, 2017

*Corresponding author: Dr. Rodrigo Ruivo, Avenida Fernando Pessoa, lote 3.20.01, Bloco B, 4 A, 1990-102 Lisbon, Portugal, Tel: +351919996559;Fax: +351217507001; E-mail: rodrigo.ruivo@netcabo.pt

\begin{abstract}
Background: Adhesive capsulitis is a common cause of shoulder pain and disability. A variety of therapeutic interventions, such as physical therapy treatment, mobilization, exercise, soft tissue therapy among others are available for restoring motion and diminishing pain in patients with adhesive capsulitis. Nevertheless, the evidence for the combined usage and effectiveness of some interventions is lacking
\end{abstract}

Objective: To describe an evaluation and conservative treatment approach consisting of a specific active-exercise program, manual therapy and the aid of electro therapy for an individual with a primary adhesive capsulitis.

Design: A case report a case of primary adhesive capsulitis in a fifty-four-year-old woman is presented to illustrate clinical presentation, diagnosis and conservative management methods.

The patient was treated 2 times over a 4-month period. Active and passive range of motion of abduction, flexion and external rotation were assessed in the beginning, and after 4, 13 and 16 weeks. Intervention included low level laser therapy with sustained pressure, ultrasound, manual therapy techniques and stretching and strengthening exercises.

Results: After the 16 weeks-period treatment the patient's shoulder range of motion was full and pain free.

Conclusions: The multi-approach intervention revealed effective in treating primary adhesive capsulitis in a fifty-four-year-old woman.

Keywords: Adhesive capsulitis; exercise; rehabilitation; shoulder

\section{Introduction}

Adhesive capsulitis is well defined in the literature as a pathological condition of the shoulder complex associated with a clinical manifestation of signs and symptoms altering normal motion and pain free function of the affected upper extremity. This pathologic condition results from inflammation of the joint capsule and synovium followed by fibrosis, scarring and contracture of the capsuloligamentous complex [1]. This capsuloligamentous changes result in global loss of both passive and active range of motion (rom) of the glen humeral joint, with external rotation usually being the most restricted physiologic movement [2,3]. Recent published data suggests shoulder adhesive capsulitis occurs in $2-5 \%$ of the population, being reported to affect females slightly more than males and it is usually seen in ages between 40 and 60 years old [2, 4].

Adhesive capsulitis can be described as passing through three stages (i) frozen or pain, (ii) freezing or stiffness and (iii) thawing or recovery phase or four stages [5,2]. In the first two stages, pain is the predominant problem, and in the third and fourth stages, stiffness is the major problem. The hallmark of stage 3 and 4 is restricted rom or stiffness in the shoulder joint, exemplified by limited shoulder elevation activities. It is the author's preference to divide the condition clinically into two stages: (i) more pain than stiff and (ii) more stiff than pain [6].

Patients suffering from shoulder adhesive capsulitis face months to years of progressive pain, stiffness and disability with the average duration being 30.1 months (range 12-42 months) $[6,7]$.

Interventions for patients with adhesive capsulitis remain not consensual and poorly understood $[2,8,9]$. Treatment options documented in the literature include physical therapy treatment, corticosteroid injections, non steroidal anti-inflammatory medications, acupuncture, manipulation under anesthesia, open surgical release, and more recently, arthroscopic capsular release [10-14]. However, it is difficult to compare the results reported in these studies because of lack of documentation of the stage of adhesive capsulitis being treated, the inexistence of control group in the design or some of the treatments evidence for its effectiveness, like the acupuncture, remains uncertain $[2,11,13]$.

Based in the knowledge that restricted rom is characteristic of the adhesive capsulitis with external rotation usually being the most restricted physiologic movement and that fibrosis or scarring of the sub scapularis may be present clinically thus limiting shoulder external rotation in the adducted position it is assertion of the authors that as treatment options sub scapularis 
trigger point therapy and the low load prolonged stretch (llps) should be addressed in adhesive capsulitis treatment $[15,16]$. The llps is a time-honored technique in shoulder therapy and requires holding the joint, placing the scarred or contracted tissue under strain at the end rom, and incrementally increasing the joint's displacement, with the expectation that remodeling of the periarticular connective tissues will improve the active and passive rom $[17,18]$.

It has already been reported llps, within each patient's tolerance level, into various rotation restrictions may result in safe, effective and timely return to elevation rom $[1,19]$. nevertheless, it is important to note in which phase of adhesive capsulitis the patient is to decide to whether use the technique or not since the chosen intensity must allway be "beneath the pain threshold".

In what regards subscapularis, trigger point therapy can be used to alleviate the soft tissue restrictions present within the muscle belly. The soft tissue technique helped to achieve normal external rotation range of motion [21]. Cadaveric studies indicate that the subscapularis muscle is the most influential stabilizing structure during passive external rotation of the glen humeral joint at zero degrees of abduction in the frontal plane. The three bellies of subscapularis are strained with external rotation in the plane of scapula [22].

Besides the techniques outlined above shoulder stretching and strengthening exercises also appears to be beneficial for pain relief and functional improvement $[23,24,25]$. In what regards manual therapy there are some studies that demonstrates important benefits, such as improved rom, however, these gains have been reported to be temporary. Also there is yet limited data to support one form of manual therapy versus another $[12,2,11]$.

Taking all into account it can be said treating adhesive capsulitis and restoring elevation in a time-efficient manner remains a challenging problem without a consensus about the best therapeutic intervention [26]. This article aims to present a report of an evaluation and conservative treatment approach of a primary adhesive capsulitis in a middle age woman.

\section{Case report}

\section{Patient history}

A fifty-four year old female presented with left shoulder pain and rom restrictions. Pain had started insidiously in the left shoulder four-months before the first clinical assessment. At that time, she saw her family physician that gave her antiinflammatory medications and injected cortisone into her left shoulder. Despite the reduction of pain symptoms for the first three weeks this relief was only transitory and continuing to have pain and left shoulder movement restriction, that got worse, she saw an orthopedic surgeon who injected her left shoulder with cortisone and recommended physical therapy. At this time the patient presented to the author's clinic with a fivemonth history of dull and achy pain in the left shoulder without being able to identify a specific traumatic situation. She also complained of not being able to move her left arm, mainly in external rotation, and having a hard time dressing and washing herself. The pain was aggravated by some movements of the left arm, lying on the left arm and she was awakened at night when she rolled onto the affected arm. The patient self-report section of American shoulder and elbow surgeons standardized shoulder assessment form was completed at the initial evaluation and the patient scored 45 points.

\section{Examination}

Our patient was in end of phase one at her initial visit to our office. On examination the patient left gleno-humeral joint active ranges of motion (rom) were: in adducted position external rotation 10 degrees, forward flexion 80 degrees, and abduction 43 degrees. A slightly internally rotated left scapula and a lack of disassociation of the scapula and humerus were identified during active elevation of the arm in the plane of the scapula through visual observation. The left glenohumeral joint passive rom was 15 degrees in external rotation and 90 degrees in forward flexion (Table 1). The opposite extremity was measured for comparison and was found to be within normal limits in both active and passive rom. In the left shoulder the patient tested positive on the palm up test, on the "full can" test and the belly test. Besides the pain $(6 / 10)$, specially referred to the insertion of the deltoid, the deltoid muscle region and the bicipital tendon, prominent weakness $(3 / 5)$ were noted during manual muscle testing of both the supraspinatus in the 'full can' position and the subscapularis while performing the belly test. Mild deficits were also noted during testing of the infraspinatus and teres minor, middle and lower trapezius which were graded with a 4/5. Trigger points were identified upon palpation of the superior and inferior lateral aspect on the anterior surface of the subscapularis muscle belly with the patient positioned in supine with the humerus supported in an abducted and externally rotated position and in the infraspinatus, teres minor, upper trapezius and in pectoralis minor. At the end of the physical examination, the identifying signs and symptoms lead to the clinical diagnosis of the left shoulder adhesive capsulitis.

Table 1: Improvement of the patient's left shoulder active and passive range of motion with treatment

\begin{tabular}{|l|l|l|l|l|}
\hline \multirow{2}{*}{ ROM } & & Abduction & Flexion & $\begin{array}{l}\text { External } \\
\text { Rotation }\end{array}$ \\
\hline \multirow{2}{*}{ Initial } & Active & 43 & 80 & 10 \\
\cline { 2 - 5 } & Passive & 50 & 90 & 15 \\
\hline \multirow{2}{*}{ At 4-weeks } & Active & 65 & 110 & 17 \\
\cline { 2 - 5 } & Passive & 75 & 118 & 20 \\
\hline \multirow{2}{*}{ At 16-weeks } & Active & 150 & 158 & 72 \\
\cline { 2 - 5 } & Passive & 168 & 170 & 80 \\
\cline { 2 - 5 } & Active & full & full & full \\
\cline { 2 - 5 } & Passive & full & full & full \\
\hline
\end{tabular}

*ROM - range of motion 


\section{Intervention}

Following the examination the patient began a physical therapy treatment. Sessions were performed twice a week, approximately 1 hour, with the supervision of a qualified shoulder specialist. The focus of treatment was to regain active and passive rom and then to re-establish scapulo-humeral rhythm by improving strength and mobility of the shoulder complex allowing the patient to return to daily activities and symptom free. In general, we divided the protocol treatment in the protocol for the first adhesive capsulitis phase, where the patient still had pain, and a protocol for the second phase, characterized for more stiffness than pain (Table 2).
In the first phase, during the first month, the physical therapy mainly aimed at the pain symptoms diminishing, but also at the beginning of rom restoration and to stimulate appropriate muscle activation and promote muscular endurance. Treatment consisted of low-level laser therapy (lllt), soft tissue massage in subscapularis and upper trapezius, manual scapular tilt distraction, passive movements, sleeper stretch exercise and a progressive resistive exercise program to address weakness and postural adaptations of the rotator cuff and scapula rotator muscles. In this initial phase therapeutic exercise were initiated using high repetitions (12-15 x 2- 3 sets) and moderate to light weight with an emphasis on pain free motion. The exercises were selected to target specific musculature identified during

Table 2: Phased intervention during the treatment of the subject in the case report

\begin{tabular}{|c|c|c|c|}
\hline $\begin{array}{l}\text { Physical Therapy } \\
\text { Treatment }\end{array}$ & Phase I (Week 1-4) Pain > Stiff Phase & $\begin{array}{c}\text { Phase II (week } 5 \text { - 13) Stiff }>\text { Pain } \\
\text { Phase }\end{array}$ & $\begin{array}{c}\text { Late Phase II (week 14-16) Stiff > } \\
\text { Pain Phase }\end{array}$ \\
\hline $\begin{array}{l}\text { Low Level Laser Therapy } \\
\text { with sustained pressure }\end{array}$ & $\begin{array}{c}8 \text { minutes (Moderate Pressure on Trigger } \\
\text { Points) } 0^{\circ} \text { Abdution }\end{array}$ & $\begin{array}{l}8 \text { minutes (Moderate Pressure on } \\
\text { Trigger Points) } 0^{\circ} \text { Abdution } \& 30^{\circ} \\
\text { Abduction in plane of the scapula }\end{array}$ & $\begin{array}{l}4 \text { minutes (Moderate Pressure on } \\
\text { Trigger Points) } 30^{\circ} \text { Abdution } \& 30^{\circ} \\
\text { Abduction in plane of the scapula }\end{array}$ \\
\hline Ultrasound $1,6 \mathrm{w} / \mathrm{cm} 2, \mathrm{t}-4^{\prime}$ & 5 minutes & $\operatorname{xxxxx}$ & $\mathrm{xxxx}$ \\
\hline ScapularTilt\&Distraction & 5 minutes manual scapular distraction & 5 minutes manual scapular distraction & $\mathrm{xxxx}$ \\
\hline TriggerPoints Therapy & $\begin{array}{c}5 \text { minutes in subscapularis infraspinatus, } \\
\text { teres minor, upper trapezius and in } \\
\text { pectoralis minor }\end{array}$ & $\begin{array}{l}5 \text { minutes in subscapularis } \\
\text { infraspinatus, teres minor, upper } \\
\text { trapezius and in pectoralis minor }\end{array}$ & When necessary \\
\hline FulcrumTechnique & 8 minutes & 5 minutes & $\operatorname{xxxxx}$ \\
\hline LowLoadProlongedStretch & $\begin{array}{l}\text { Variable (Since no stretches if not tolerated } \\
\text { to stretches lasting no more than } 5 \text { secs, } 2-3 \\
\text { times a session until sets of } 15 \text { secs). No } \\
\text { weight or } 0,5 \mathrm{~kg} \text { weight } 0^{\circ} \text { abduction }\end{array}$ & $\begin{array}{l}10 \text { minutes } 2 \mathrm{~kg} \text { weight } \\
0^{\circ} \text { abduction } \& 30^{\circ} \mathrm{Abduction} \text { in the } \\
\text { plane of the scapula }\end{array}$ & $\begin{array}{l}8 \text { minutes } 2 \mathrm{~kg} \text { weight } \\
0^{\circ} \text { abduction } \& 30^{\circ} \mathrm{Abduction} \text { in the } \\
\text { plane of the scapula }\end{array}$ \\
\hline $\begin{array}{l}\text { IntelligentPendulum } \\
\text { Exercise }\end{array}$ & $2 * 81 \mathrm{~kg}$ dumbell & $2 * 82 \mathrm{~kg}$ dumbell & $2 * 82 \mathrm{~kg}$ dumbell \\
\hline $\begin{array}{l}\text { Push Swiss ball against } \\
\text { the wall }\end{array}$ & $2 * 12-15$ & $3 * 12-15$ & $* * *$ \\
\hline $\begin{array}{l}\text { External rotation at } 0^{\circ} \\
\text { abduction }\end{array}$ & $3 * 15$ light tube & $3 * 8-12$ tube or $5 \mathrm{~kg}$ pulley & $3 * 6-8$ tube or $8 \mathrm{~kg}$ pulley \\
\hline Prone Extension & $3 * 15$ & $3 * 8-121 \mathrm{~kg}$ dumbell & $3 * 6-82 \mathrm{~kg}$ dumbell \\
\hline Belly Exercise & $2 * 15$ & $3 * 12-15$ & $\operatorname{xxxx}$ \\
\hline Low Row & $3^{*} 15$ tube & $3 * 8-12$ tube or $15 \mathrm{~kg}$ weight machine & $3 * 6-1820 \mathrm{~kg}$ weight machine \\
\hline Sleeper Stretch & 6 minutes $3^{*}\left(1^{\prime} \mathrm{ON}+10 \mathrm{FF}\right)$ & 6 minutes $3^{*}\left(1^{\prime} \mathrm{ON}+10 \mathrm{FF}\right)$ & 6 minutes $3^{*}\left(1^{\prime} \mathrm{ON}+1 \mathrm{OFF}\right)$ \\
\hline Dynamic Hug & $\operatorname{xxxxx}$ & $3 * 12-1510 \mathrm{~kg}$ pulley & 3*8-12 15 kg pulley \\
\hline $\begin{array}{c}\text { Prone Horizontal } \\
\text { Abduction with ER below } \\
90^{\circ} \text { Abduction } \\
\end{array}$ & $\mathrm{xxxx}$ & $3 * 8-15$ & 3*8-12 $151 \mathrm{~kg}$ dumbell \\
\hline Scaption & $\operatorname{xxxxx}$ & $2 * 12$ & $3 * 121 \mathrm{~kg}$ dumbbell \\
\hline Lift Off Exercise & $\operatorname{xxxxx}$ & $2 * 12$ & $3 * 12$ manual resistance \\
\hline $\begin{array}{c}\text { Subscapularis IR Diagonal } \\
\text { Exercise }\end{array}$ & $\operatorname{xxxxx}$ & $3 * 8-1210 \mathrm{~kg}$ pulley & $3 * 8-1215$ kg pulley \\
\hline Push up plus & $\mathrm{xxxx}$ & $\operatorname{xxxxx}$ & $\begin{array}{c}\text { Body weight push up with arms in a } \\
\text { elevated surface }\end{array}$ \\
\hline Core Exercises & $\operatorname{xxxxx}$ & $\begin{array}{l}\text { Wall plank ( } 2 * 10 \text { seconds) ; Lift } 2 * 151 \\
\text { kg dumbbell Pallof press }(2 * 12) \text { tube }\end{array}$ & $\begin{array}{l}\text { Plank and side plank with knees } \\
\left(3^{*} 10 \text { seconds) ; Lift } 2 * 122 \mathrm{~kg}\right. \\
\text { dumbbell Pallof press }\left(3^{*} 10\right) \text { tube }\end{array}$ \\
\hline $\begin{array}{l}\text { Hip Exercises for the } \\
\text { medium and maximu } \\
\text { gluteus }\end{array}$ & $\operatorname{xxxxx}$ & Wall squat swiss ball $\left(3^{*} 12\right)$ & $\begin{array}{l}\text { TRX Squat and Single Leg Squat } \\
\qquad\left(3^{*} 12\right)\end{array}$ \\
\hline
\end{tabular}


the examination as having less than optimal strength. Specific exercises of the rotator cuff and scapular rotators eliciting high emg activity of the targeted musculature were performed. Manual mobilization of the scapula and the fulcrum technique was utilized in phase i and ii. In the manual mobilization technique the patient was positioned in a side-lying position with the injured upper extremity relaxed at top at the patient's side. The physical therapist is posterior to the patient with inner hand thread under the involved extremity and supporting the anterior glenohumeral joint, grasps the vertebral border and tilts the scapula away from the thoracic wall (Figure 1) [27]. This technique is used in cases of restriction in external rotation. In the fulcrum technique (Figure 2), used to mobilize the posterior capsule, the patient is lying on her stomach and the therapist puts the closest forearm under the anterior part of the glenohumeral joint, the other hand is placed just proximal to the elbow[27]. Then while pushing up on the patient's glenohumeral joint with the forearm, the therapist also pulls down on the elbow to create a stretch on the posterior aspect off the glenohumeral joint. Also used in both phases, even if with different durations and positions, we can highlight the use of the lllt and the sleeper stretch exercise. In what concerns lllt we used the laser with deep sustained pressure to relieve trigger points in the subscapularis muscle belly [21] (Figure 3). Pressure was applied over the trigger point identified in the examination and modified according to patient tolerance.

Regarding the sleeper stretch exercise, this is considered to have a beneficial effect in the increasing of the rom, of the acromiohumeral distance and in cases of posterior shoulder tightness [28]. By the end of the fourth week of treatment, the patient demonstrated better active and rom in all direction. The active er, forward flexion and abduction improved to $17^{\circ}, 110^{\circ}$ and $65^{\circ}$ respectively, whereas in the passive rom the er improved to $20^{\circ}$. It was also reported that there was better scapula control during the resistance exercises, and more muscular endurance in rotator cuff. In phase ii, with a less painful and stiff shoulder, we aimed to almost fully achieve the normal rom and to continue stimulating appropriate muscle activation and promote muscular strength.

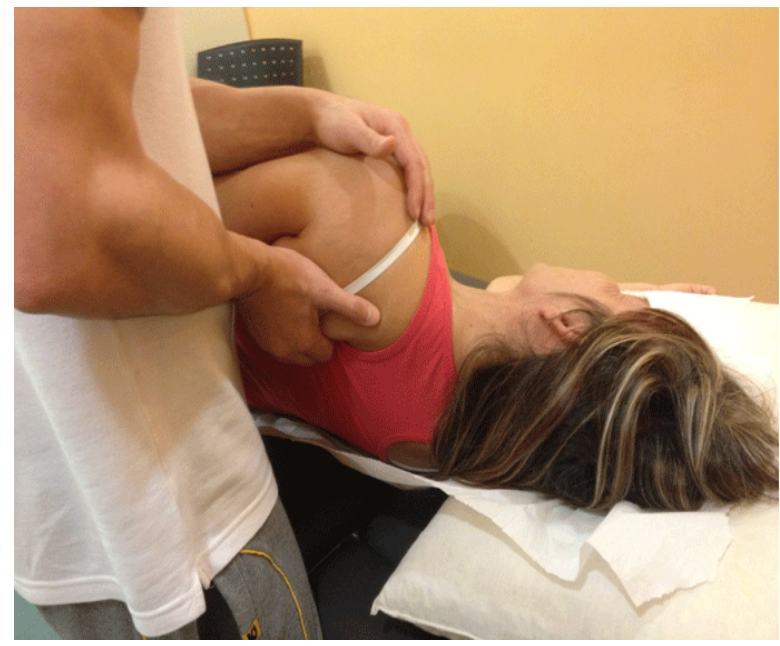

Figure 1: Manual mobilization of thescapula

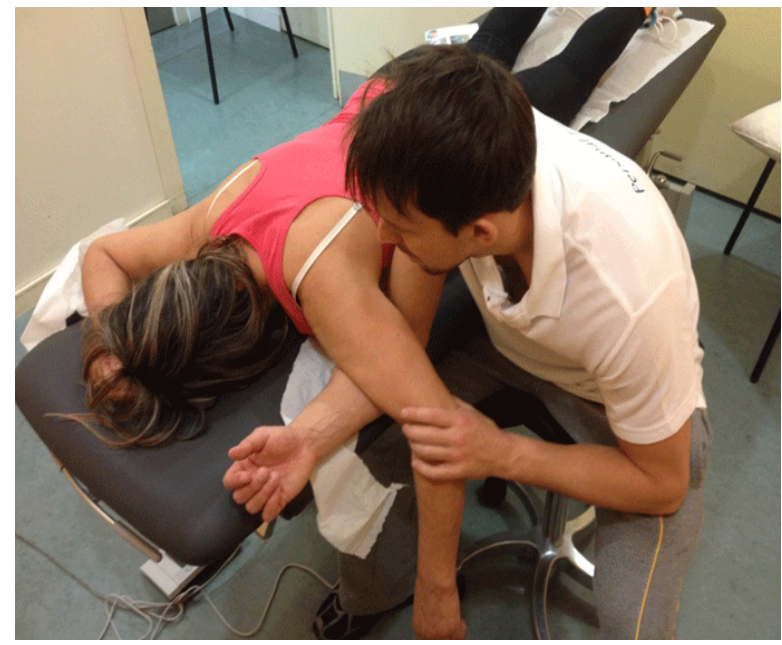

Figure 2: Fulcrum technique

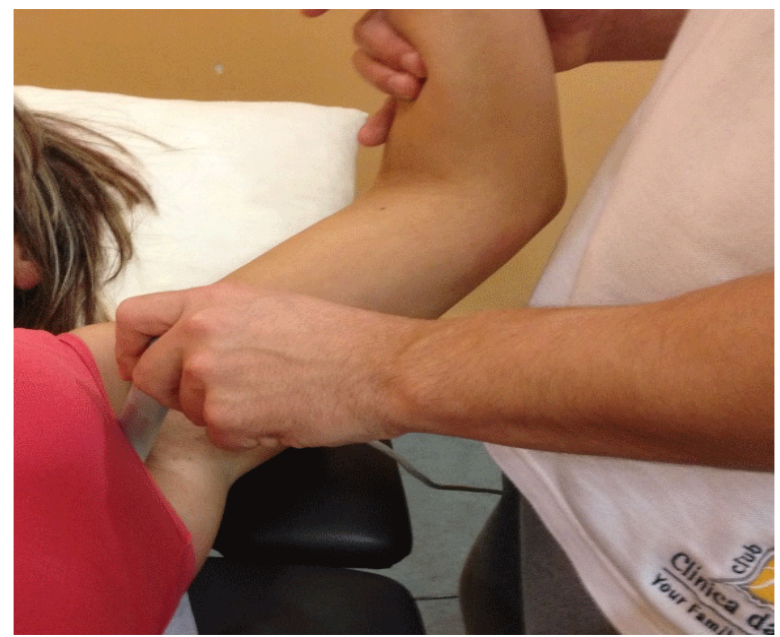

Figure 3: Low-level laser therapy for the subscapularis

Regarding llps, this technique was mostly used in the second phase, within the patient's tolerance level. Llps into glenohumeral external rotation was applied continuously for 12 and 8 minutes in phase ii and late phase ii respectively. The patient was positioned in the supine position with the shoulder supported on a foam wedge with $30^{\circ}$ abduction in plane of the scapula (phases ii-late ii), allowing gravity to produce the intended stretch into external rotation (Figure 4).

In what concerns the strength training we performed the same exercises using increased weight with fewer repetitions (8-12 reps $\times 3$ sets) in order to emphases more on muscular strengthening of the shoulder complex. New exercises were added like the prone horizontal abduction with er below $90^{\circ}$ abduction, that have been shown to illicit high activity in the scapula retractors such as the medium trapezius and lower trapezius and low activity of the upper trapezius confirming its clinical relevance [29,30], the scaption, targeting the supraspinatus, the push up with plus and exercises like the dynamic hug and the subscapularis internal 


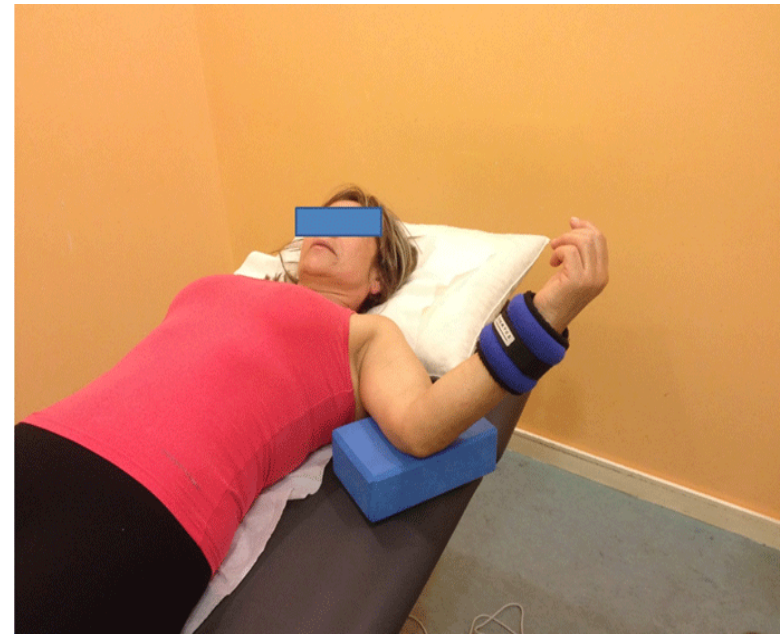

Figure 4: Low-load prolonged stretch with $30^{\circ}$ abduction in plane of the scapula

rotation diagonal exercise that highly elicit the subscapularis [29].

Simultaneously, taking into consideration a total body approach concept, core and hip exercises were also performed. By the end of the 13th week, in transition of phase (ii) to late phase (ii), the patient had $90 \%$ of the rom in all movement Directions. Finally, in the late phase ii, during 4 weeks, since week 14 to 16 , we had the goal to fully achieve the normal rom of every movement, to balance the ratios of muscle strength and to re-establish scapulohumeral rhythm, having our patient to normally return to daily activities and symptom free. The resistance of the therapeutic exercise targeting the rotator cuff and scapular rotators was increased accordingly to the patient's tolerance and ability to demonstrate proper technique throughout the exercise. We prescribed low repetition exercise (6-8 reps $x 3$ sets) with higher resistance. In the end, the patient had full active elevation without evidence of compensatory movement patterns, symmetrical scapulae, pain free grades of 5/5 during manual muscle testing of the rotator cuff and scapular rotator musculature, improved passive rom to 85 degrees of external rotation at zero degrees of abduction. The ases questionnaire was answered again and the patient scored 88 points. (Table 2) identifies the prescription of therapeutic exercise and phase in which specific therapeutic interventions were implemented in relation to this case Report.

It must be emphasized that even though the patient had only two guided treatment sessions a week, she had to perform twice a week a home-exercise program with the strengthening and stretching exercises specific of each phase and that she used to do in the treatment sessions. The exercises and weight selection were responsibility of the physical therapist, that every week in the guided sessions confirmed a proper technique in the exercises execution.

The participation of the patient was voluntary, and written informed consent was obtained prior to the commencement of the intervention.

\section{Discussion}

This study presents an effective treatment approach in a case of primary adhesive capsulitis in a fifty-four-year-old female. After the 16 weeks-period treatment the patient's shoulder rom was full and pain free. To our knowledge this treatment approach has the strength of combining a variety of treatment techniques, such as manual therapy or low load prolonged stretch among others. It is also assertion of the authors that a well guided and progressive resistance training program, targeting the right muscles is crucial for the effectiveness of the intervention as it is our conviction that subscapularis is often overlooked and therefore undertreated. Identifying the subscapularis' potential involvement in patients with adhesive capsulitis pathology may be helpful in gaining a greater insight into shoulder dysfunction and expand intervention options.

First of all, in the clinical examination after a full patient interview and physical examination, the perception that there was an equal restriction of active and passive external rotation, the knowledge that the radiographs were normal and that the patient didn't report an obvious cause to the painful and stiff shoulder we classified this case report as a primary adhesive capsulitis.

Considering adhesive capsulitis characterization in two stages; (i) more pain than stiff and (ii) more stiff than pain we can report our patient was in phase one at her initial visit to our office. She indicated gradual onset of stiffness and pain, referring the location of pain more often in the insertion of the deltoid, the deltoid muscle region and at the bicipital tendon. The pain was aggravated by the shoulder movements, especially external rotation or sleeping on the involved side, and simple tasks like putting on a coat, combing the hair or fasten garments behind the back were extreme difficult or impossible [31,32]. At the beginning there was a clear active and passive glenohumeral rom restriction, with the external rotation being the most restricted physiologic movement [2], and a prominent weakness of the rotator cuff, and middle and lower trapezius.

Considering this assessment, to restore the rom and function of the shoulder, with the reestablishment of the scapulo-humeral rhythm we designed a multi-approach protocol combining effective strategies already used by other authors, such as laser therapy, low load prolonged stretch , exercise therapy, trigger point therapy and manual therapy [33,19,34-36]. In the current case report, the treating clinicians utilized a deep pressure soft tissue mobilization technique in conjunction with lllt. Lllt has been cited as a safe and effective modality to accelerate pain relief and healing $[21,37,38]$. Also, active release techniques and trigger point therapy can be effectively used to alleviate any soft tissue restrictions present within different muscles and to aid in adhesive capsulitis treatment [35]. For example, reported three cases of frozen shoulder which he successfully treated using trigger point therapy techniques. In our case report we mainly used the trigger point therapy in the subscapularis muscle, in infraspinatus, teres minor and upper trapezius [35]. With the emphasize in the subscapularis trigger point therapy we aimed 
at the restoration of the shoulder external rotation, since we know subscapularis, among other components such as coracohumeral ligament, the pectoralis major and the long head of the biceps limits shoulder external rotation $[39,21]$.

Also, a subscapularis tiltand distraction softtissuemobilization technique was used to provide oscillatory mobilization stretch in an attempt to alleviate any soft tissue restrictions present within the subscapularis muscle as illustrated in (Figure 1)[21].

Another technique we used, this one mainly in the second phase, was the llps. Splints utilizing a static progressive stretch has been shown to make improvements in the mobility of a stiff shoulder $[19,40]$. It has been shown that force applied to the tissue, accompanied by a progressively increased load, will produce a plastic deformation [41]. A case report in which end-range mobilization techniques were effective in restoring permanent changes in passive and active overhead movements in patients with adhesive capsulitis[42]. The patient was also introduced to the fulcrum technique and posterior capsule mobilizations. Both techniques try to create a stretch on the posterior aspect of the glenohumeral joint, like the sleeper stretch exercise does [27,43]. This stretching exercise was performed in the end of the exercise training program, and it is advocated it allows stretching of the posterior shoulder capsule and improving range of internal rotation $[28,44]$.

The patient also underwent to a progressive resistance exercise program under the supervision of the physical therapist early in the rehabilitation process in order to develop neuromuscular control, improve overall strength, and facilitate optimal ratios of strength of the rotator cuff and scapular rotator musculature. The designing of the intervention protocol was based in scientific evidences and the exercises selected were the one literature has proven to be the most effective for the rotator cuff and scapular rotators strengthening, based on electromyography research. Our patient was initially instructed to do pendulum exercises, pushing and circle the ball against the wall, for serratus anterior training, external rotation at $0^{\circ}$ abduction, prone extension, belly exercise and low row exercise [45]. Later on, as the pain decreased, in the second phase new exercises were added, with the same goal of strengthening the subscapularis (e.g lift off exercise), the infraspinatus, teres minor and medium and low trapezius (e.g. Prone horizontal abduction with er below $90^{\circ}$ abduction), the serratus anterior (e.g push up plus) and the supraspinatus (e.g scaption), trying ot balance the strength ratios and to re-establish scapulohumeral rhythm. Core exercises and hip exercises were longitudinal to phase (ii) and (iii).

It must be emphasized every exercises were performed pain free and besides the frequency of two treatment sessions a week with the physiotherapist, the patient also performed a homeexercise program twice a week, in opposite days of the treatment sessions, where she followed a sequence of exercises prescribed by the physical therapist.

The exercises prescribed were similar to those practiced in the treatment sessions and depended from the recovery phase and a booklet was given to the patient. Several studies has already reported the aid of therapeutic exercises in the frozen shoulder conservative treatment is beneficial in relieving the signs and symptoms of frozen shoulder [25,34].

\section{Conclusion}

No therapeutic intervention is currently universally accepted as most effective for restoring motion and diminishing pain in patients with adhesive capsulitis. In this case report study we proved the effectiveness of multi-approach intervention for primary adhesive capsulitis in a fifty- four-year-old female. In the end of 16-weeks-period the patient's shoulder rom was full and pain free. However, further research is required to identify the effectiveness of this treatment in a large scale approach.

\section{References}

1. Donatelli R, Ruivo RM, Thurner M, Ibrahim MI. New concepts in restoring shoulder elevation in a stiff and painful shoulder patient. Phys Ther Sport. 2014;15(1):3-14. Doi: 10.1016/j.ptsp.2013.11.001

2. Neviaser AS and Hannafin JA. Adhesive capsulitis: a review of current treatment. Am J Sports Med. 2010;38(11):2346-56. Doi: $10.1177 / 0363546509348048$

3. Uhthoff HK, Boileau P. Primary frozen shoulder: global capsular stiffness versus localized contracture. Clin Orthop Relat Res. 2007;456(456):79-84. Doi: 10.1097/BLO.0b013e318030846d

4. Wong PL, Tan HC. A review on frozen shoulder. Singapore Med J . 2010;51(9):694-697.

5. Reeves B. The natural history of the frozen shoulder syndrome. Scand J Rheumatol. 1975;4(4):193-196.

6. Lewis J. Frozen shoulder contracture syndrome - Aetiology, diagnosis and management. Man Ther . Elsevier Ltd; 2014;20(1):2-9. Doi: 10.1016/j.math.2014.07.006

7. Jewell DV, Riddle DL and Thacker LR. Interventions associated with an increased or decreased likelihood of pain reduction and improved function in patients with adhesive capsulitis: a retrospective cohort study. Phys Ther. 2009;89(5):419-429. Doi: 10.2522/ptj.20080250

8. Buchbinder R, Youd JM, Green S, Stein A, Forbes A, Harris A, Bennell $\mathrm{K}$, et. al. Efficacy and cost-effectiveness of physiotherapy following glenohumeral joint distension for adhesive capsulitis: a randomized trial. Arthritis Rheum. 2007;57(6):1027-1037.

9. Bal A, Eksioglu E, Gulec B, Aydog E, Gurcay E, and Cakci A. Effectiveness of corticosteroid injection in adhesive capsulitis. Clin Rehabil. 2008;22(6):503-512. Doi: 10.1177/0269215508086179

10. Castellarin G, Ricci M, Vedovi E, Vecchini E, Sembenini P, Marangon A, et. al. Manipulation and arthroscopy under general anesthesia and early rehabilitative treatment for frozen shoulders. Arch Phys Med Rehabil. 2004;85(8):1236-1240. Doi: 10.1016/j.apmr.2003.12.032

11. Vermeulen HM, Rozing PM, Obermann WR, le Cessie S, Vileland VT. Comparison of high-grade and low-grade mobilization techniques in the manage- ment of adhesive capsulitis of the shoulder: randomized controlled trial. Phys Ther. 2006;86:355-368.

12. Yang JL, Chang CW, Chen SY, Wang SF, Lin JJ. Mobilization techniques in subjects with frozen shoulder syndrome: randomized multipletreatment trial. Yoon. Phys Ther. 2007;87(10):1307-1315. Doi: 10.2522/ptj.20060295

13. Maund E, Craig D, Suekarran S, Neilson A, Wright K, BS. Management of frozen shoulder: a systematic review and cost-effectiveness analysis. 
Heal Technol Assess. 2012;16(11):1-264. Doi:10.3310/hta16110

14. Kivimäki J, Pohjolainen T, Malmivaara A, Kannisto M, Guillaume J, Seitsalo S, et. al. Manipulation under anesthesia with home exercises versus home exercises alone in the treatment of frozen shoulder: a randomized, controlled trial with 125 patients. J Shoulder Elb Surg. 2007;16(6):722-726. Doi: 10.1016/i.jse.2007.02.125

15. Turkel S, Panio M, Marshall JL, Girgis FG. Stabilizing Mechanisms Preventing Anterior Dislocation of the Glenohumeral Joint. J Bone Jt Surg Am. 1981;63(8):1208-1217.

16. Donatelli R. Physical Therapy of the Shoulder. 5th ed. New York; Churchill Livingstone: 2012.

17. Bonutti P, Hotz M, Gray T, Cremens M, Leo C, \& Beyers M. Joint contracture rehabilitation: static progressive stretch. J Bone Jt Surg. 1998;22(1).

18. Bonutti PM, McGrath MS, Ulrich SD, McKenzie S a, Seyler TM, Mont M. Static progressive stretch for the treatment of knee stiffness. Knee. 2008;15(4):272-276.

19. Dempsey AL, Mills T, Karsch RM, Branch TP. Maximizing total end range time is safe and effective for the conservative treatment of frozen shoulder patients. Am J Phys Med Rehabil. 2011;90(9):738745. Doi: 10.1097/PHM.0b013e318214ed0d

20. Bonutti PM, Windau JE, Ables BA MB. Static progressive stretch to reestablish elbow range of motion. Clin OrthopRelatRes. 1994;303:128-134.

21. Thurner MS, Donatelli R, Bascharon R. Subscapularis syndrome: a case report. Int J Sports Phys Ther. 2013;8(6):871-882.

22. Muraki T, Aoki M, Uchiyama E, Takasaki H, Murakami G, Miyamoto S. A cadaveric study of strain on the subscapularis muscle. Arch Phys Med Rehabil [Internet]. 2007;88(7):941-946.

23. Geraets JJ, Goossens ME, de Groot, IJ, de Bruijn CP, de Bie RA, Dinant GJ, et al. Effectiveness of a graded exercise therapy program for patients with chronic shoulder complaints. Aust J Physiother. 2005;51(2):8794.

24. Hand C, Clipsham K, Rees JL, and Carr AJ. Long-term outcome of frozen shoulder. J Shoulder Elb Surg. 2008;17(2):231-236.

25. Levine WN, Kashyap CP, Bak SF, Ahmad CS, Blaine TA, and Bigliani LU Nonoperative management of idiopathic adhesive capsulitis. J Shoulder Elb Surg. 2007;16(5):569-573. Doi: 10.1016/i.jse.2006.12.007

26. Johnson AJ, Godges JJ Zimmerman G, Ounanian LL. The effect of anterior versus posterior glide joint mobilization on external rotation range of motion in patients with shoulder adhesive capsulitis. Orthop Sport Phys Ther. 2007;37(3):88-99.

27. Donn Dimond, Donatelli Robert MK. The bare minimum: Donatelli shoulder method assessment and treatment. 2nd ed. Charleston; 2011.

28. Maenhout A, Van Eessel V, Van Dyck L, Vanraes A CA. Quantifying Acromiohumeral Distance in Overhead Athletes With Glenohumeral Internal Rotation Loss and the Influence of a Stretching Program. Am J Sport Med. 2012;40(9):2105-2112.

29. Reinold MM, Escamilla RF, Wilk KE. Current concepts in the scientific and clinical rationale behind exercises for glenohumeral and scapulothoracic musculature. J Orthop Sports Phys Ther.

\section{9:39(2):105-117. Doi: 10.2519/jospt.2009.2835}

30. Cools AM, Dewitte V, Lanszweert F, Notebaert D, Roets A, Soetens B, et al. Rehabilitation of scapular muscle balance: which exercises to prescribe? Am J Sports Med. 2007;35(10):1744-1751.

31. Grubbs N. Frozen shoulder: A review of literature. JOSPT. 1993;18(3):479-487.

32. Kazemi M. Adhesive capsulitis: a case report. J Can Chiropr Assoc. 2000;44(3):169-176.

33. Taverna E, Parrini M CP. Laser therapy versus placebo in the treatment of some bone and joint pathology. Minerva Ortop E Traumatol. 1990;41:631-636.

34. Russell S, Jariwala A, Conlon R, Selfe J, Richards J, Walton M. A blinded, randomized, controlled trial assessing conservative management strategies for frozen shoulder. J Shoulder Elbow Surg. 2014;23(4):500507. Doi:10.1016/j.jse.2013.12.026

35. Ferguson L. Treating shoulder dysfunction and a frozen shoulder. Chirop Tech. 1995;7(3):73-81.

36. Favejee MM, Huisstede BM, Koes BW. Frozen shoulder: the effectiveness of conservative and surgical interventions--systematic review. Br J Sports Med. 2011;45(1):49-56. Doi: 10.1136/bjsm.2010.071431

37. Bjordal J, Couppe C, Ljunggren A. Low level laser therapy for tendinopathy: evidence of a dose- response pattern. Phys Ther Rev. 2001;6:91-99.

38. Huang Y, Chen A, Carroll J, Hamblin MR. Bi-phasic dose response in low level light therapy. Dose Response. 2009;7(4):358-383. Doi: 10.2203/dose-response.09-027.Hamblin

39. McGahan PJ, Patel H, Dickinson E, Leasure J, Montgomery W. The effect of biceps adhesions on glenohumeral range of motion: a cadaveric study. J Shoulder Elbow Surg . 2013;22(5):658-665. Doi: 10.1016/j. jse.2012.07.003

40. Mcclure PW, Michener LA, Andrew R. Research Report Shoulder Function and 3- Dimensional Scapular Kinematics in People With and Without Shoulder. Phys Ther. 2006;86(8):1075-1090.

41. Light KE, Nuzik S, Personius W, Barstrom A. Low-Load Prolonged Stretch vs . High- Load Brief Stretch in Treating Knee Contractures. J Am Phys Ther Assoc. 1984;330-333.

42. Vermeulen HM, Obermann WR, Burger BJ, Kok GJ, Rozing PM, and van Den Ende $\mathrm{CH}$. End-range mobilization techniques in adhesive capsulitis of the shoulder joint: a multiple-subject case report. Phys Ther. 2000;80(12):1204-1213.

43. Bowen MK, Warren RF. Ligamentous control of shoulder stability based on selective cutting and static translation experiments. Clin Sports Med. 1991;10(4):757-782.

44. Laudner KG, Sipes RC, Wilson JT. The acute effects of sleeper stretch on shoulder range of motion. J Athl Train. 2008;43(4):359-363. Doi: 10.4085/1062-6050-43.4.359

45. Martins J, Tucci HT, Andrade R, Araújo RC, Bevilaqua-Grossi D, Oliveira AS. Electromyographic amplitude ratio of serratus anterior and upper trapezius muscles during modified push-ups and bench press exercises. J Strength Cond Res. 2008;22(2):477-484. Doi: 10.1519/ JSC.0b013e3181660748 